\title{
TECNOLOGIA NO ENSINO DE FÍSICA: OS AMBIENTES VIRTUAIS DE APRENDIZAGEM (AVAS) E OS SIMULADORES
}

\section{ARTIGO ORIGINAL}

SILVA, Raila Leal ${ }^{1}$

SILVA, Givanildo Sales ${ }^{2}$

MACÊDO, Haroldo Reis Alves de ${ }^{3}$

SILVA, Raila Leal. SILVA, Givanildo Sales. MACÊDO, Haroldo Reis Alves de. Tecnologia no ensino de física: Os ambientes virtuais de aprendizagem (AVAs) e os simuladores. Revista Científica Multidisciplinar Núcleo do Conhecimento. Ano 05, Ed. 08, Vol. 08, pp. 136-147. Agosto de 2020. ISSN: 2448-0959, Link de acesso: https://www.nucleodoconhecimento.com.br/educacao/tecnologia-no-ensino

\section{RESUMO}

Atualmente vivenciamos a era tecnológica, em que a comunicação e a informação acontecem de maneira mais rápida que a convencional, além disso, tornou-se mais fácil o acesso ao conhecimento em diversas áreas. Considerando a área educacional, das diversas formas tecnológicas existentes, destacam-se o uso de Ambientes Virtuais de Aprendizagem (AVAs) que são muito utilizados na educação a distância e que podem servir também como complemento em aulas presenciais configurando-se como alternativa pedagógica para o sucesso do processo de ensino e aprendizagem. Os simuladores são outra técnica pedagógica que podem ser utilizados em sala, pois

\footnotetext{
${ }^{1}$ Graduação em andamento em Física.

${ }^{2}$ Especialista em Especialização em Ensino de Física (2018), Licenciado em Física (2014).

${ }^{3}$ Orientador. Doutor em Ciência e Engenharia de Materiais, Mestre em Ciência e Engenharia de Materiais, Licenciado em Física.
} 
também possibilitam aos estudantes autonomia e aproximação com a realidade encontrada, além de ser uma importante ferramenta quando não se tem laboratório. Desta forma, este trabalho aponta propostas para o ensino de Física, através de duas metodologias, uma é a utilização dos AVAs e a outra com a utilização de simuladores. Foi realizado uma pesquisa no Centro Estadual de Tempo Integral Marcos Parente onde verificou-se que a grande maioria dos estudantes do ensino presencial não conhecem ou ao menos sabem o que é um AVA e que apenas 10,7\% afirmam já ter usado simuladores.

Palavras-Chave: AVAs, simulador, ensino de física, aprendizagem.

\section{INTRODUÇÃO}

Devido ao avanço tecnológico a educação nos dias atuais vem passando por inúmeras transformações, consequentemente o papel do professor em sala de aula vem se modificando a cada dia. Antes consistia em aulas expositivas, uso de livros e apostilas, no entanto, hoje estão sendo deixados de lado, o aluno não tem mais interesse por aulas "tradicionais", estão sempre em busca de novidades, as aulas em que somente o professor é conhecedor das informações estão fora de contexto. Junto a isso surge uma corrida por atualizações do mundo contemporâneo.

Hoje seria impossível descartar essa realidade no âmbito educacional, embora seja preciso inovar a educação. Quando a internet é usada de forma adequada, o modo de ensinar e aprender torna-se uma ferramenta poderosa no processo de ensino/aprendizagem. Nesse processo se englobam todos inseridos no âmbito educacional, mais quando se fala de mudança na educação, a iniciativa tomada deve vir primeiramente do professor como diz Silva (2015), os educadores precisam adaptar suas aulas, buscar métodos para tornar a aprendizagem desejável.

Pensando nisso, foi desenvolvido este trabalho com o enfoque em fazer aplicações dos ambientes virtuais e simuladores no ensino de física para que os alunos se apropriem de ferramentas úteis que permitam a sustentação de conceitos e que tragam motivação para a aprendizagem. Com isso, espera-se que os alunos sejam 
sujeitos ativos no processo de ensino/aprendizagem, para Ribeiro (2005), é preciso adotar mudanças nos métodos educacionais tomando medidas eficazes para que os alunos tenham percepções cognitivas.

\section{FUNDAMENTAÇÃO TEÓRICA}

\section{AMBIENTES VIRTUAIS}

Atualmente vivenciamos a era tecnológica, em que a comunicação e a informação acontecem de maneira mais rápida e convencional, além disso, tornou-se mais fácil o acesso ao conhecimento em diversas áreas. De acordo com Neto e Vital (2010) a interação com a tecnologia deve ser associada à educação de maneira organizada e planejada para a melhoria da sociedade. No entanto, mesmo com esses avanços muitas pessoas ainda não têm acesso a tais meios ou mesmo não estão preparadas para a realidade social e histórica. Segundo Kohn e Moraes (2007), as modificações tecnológicas não acontecem de maneira igual e em todos os lugares e ao mesmo tempo, trata-se de um processo temporal.

Das diversas formas tecnológicas existentes, destacam-se o uso de Ambientes Virtuais de Aprendizagem (AVAs) que são muito utilizados na modalidade de educação à distância (EAD), e também ampliam o ensino presencial quando utilizados como instrumento educacional, configurando-se como alternativa pedagógica para o sucesso do processo de ensino e aprendizagem, afirma Martins; Tiziotto e Cazarini (2016). Os ambientes informatizados de aprendizagem (AIA) de acordo com Santos (2010) são ferramentas que possibilitam aos alunos desenvolver capacidades intelectuais como 0 ato de tornarem-se autônomos, críticos e investigativos, dandoIhes a oportunidade de buscar conhecimentos por caminhos diversificados.

A utilização dos ambientes virtuais no ensino/aprendizagem quando realizada de forma coerente, adequada, didática e pedagógica contribui para uma educação contextualizada, interativa e dinâmica, possibilitando maior rendimento no ensino aprendizagem do aluno. Leão et al (2013), ressalta que a conciliação do ensino presencial com ambientes virtuais traz inúmeros benefícios na construção do 
conhecimento e favorece a coletividade. Ribeiro; Mendonça e Mendoça (2007), afirmam ainda que o espaço virtual oferta inúmeros conteúdos de forma organizada, interativa.

Dessa forma o professor em sala de aula precisa apropriar-se de métodos para sua adequação perante as mudanças tecnológicas, trazendo-as em seu favor, de forma a conciliar as ferramentas ofertadas em seu plano de ensino, desenvolvendo uma nova didática. Beneli (2014) reforça que alunos e professores precisam se consolidar no mesmo objetivo, o de ensino-aprendizagem, para que essa ação se torne mais sólida e eficiente. No entanto, para que isso ocorra, ambos precisam ser participantes do mesmo processo.

\section{SIMULADORES}

Dentro do contexto sobre métodos de ensino/aprendizagem através do uso de tecnologias, os simuladores são uma ferramenta pedagógica que podem ser utilizados em sala, pois possibilitam aos estudantes autonomia e aproximação com a realidade encontrada. Além disso, Pereira et al (2010) aborda que a utilização de softwares não apenas facilita o ensino e a aprendizagem, como também permite aos alunos adquirir técnicas para aprender de forma prazerosa, interessante e desafiante.

Para Zampier (2016) relacionar tecnologias à educação é um método pedagógico que ajuda a enfrentar as dificuldades encontradas atualmente na sociedade, como ministrar aulas para as novas demandas de alunos bem como a necessidade de haver interação entre professor e alunos. Oliveira (2010) ressalta a importância da interação entre educadores e educandos, pois para ele o espaço educacional constituído por trocas de conhecimento consiste em uma melhor aprendizagem e torna as aulas mais produtivas.

Em decorrência disso, a utilização de simuladores possibilita uma aula contextualizada, onde o aluno deixa de ser receptor de informações e apenas o professor o sujeito ativo no ensino/aprendizagem, entendida como uma "educação bancária" a autora Martins et al (2015) denomina como sendo uma educação 
opressora que impede o questionamento de determinado assunto, além de deixar o aluno desestimulado pela aula. Já com a simulação é possível ao aluno entender melhor o conteúdo sem necessitar de memorização, pois a participação e o envolvimento entre os sujeitos no processo permite a troca de conhecimento, além disso, Sousa (2011) aborda que a aplicação dos simuladores precisa ser de forma adequada, para isso, antes da utilização do simulador, deve-se realizar aulas teóricas sobre o conteúdo, para que assim a simulação seja entendida como uma comprovação dos conceitos visto na aula.

\section{DESAFIOS NO ENSINO DE FÍSICA}

A disciplina de Física é vista como uma área de difícil compreensão por muitas vezes ser expressa por meio de linguagem puramente matemática. Por isso os alunos se atentam em aprender apenas a "fórmula" deixando de conhecer os conceitos físicos. Para Concheti (2015) a Física está diretamente relacionada com a Matemática, mas ao pensar no ensino de Física, é preciso adotar medidas para enfatizar os conceitos físicos, não apenas matematizando a física. Fernandes (2016) ressalta ainda que quando a disciplina é trabalhada assemelhada ao contexto social, facilita a aprendizagem e não há prática de decorar conteúdo.

Na disciplina de Física alguns conceitos são abstratos e necessitam ser demonstrados a partir de experimentos. Sabe-se que boa parte das instituições de ensino não disponibilizam laboratórios e que a experimentação é forte aliada no aprendizado da física. A ausência de laboratórios muitas vezes se dá pela falta de estrutura física e financeira da escola, e como consequência disso, os alunos não tem acesso a aulas práticas de determinado conteúdo.

Contudo, quando são adotados métodos como proposta de ensino para suprir essa necessidade a exemplo disso, a tecnologia, a realidade encontrada na escola dificulta a implantação dessa metodologia. Para Schuhmacher; Filho e Schuhmacher (2017) existe três grupos considerados obstáculos para implementação das TICs na educação, a estrutural que está relacionado a organização da gestão e docentes de forma conjunta. O obstáculo epistemológico que se refere sobre a dificuldade de 
novos conceitos para a ciência e o didático está relacionado aos métodos que o professor se dispõe para mediação do conhecimento.

Diante disso, faz-se necessário se adequar ao ambiente educacional em que está inserido, utilizando ferramentas apropriadas para executar as propostas pedagógicas ofertando ao público-alvo ensino de qualidade e novas propostas, com o intuito de aproximá-los da sua realidade. A utilização das tecnologias como aponta Araújo et al (2017) é de suma importância para auxiliar o ensino desenvolvendo uma formação reflexiva.

\section{METODOLOGIA}

A metodologia adotada foi revisão bibliográfica e pesquisa exploratória realizada com 28 (vinte e oito) alunos do primeiro ano do Ensino Médio do Centro Estadual de Tempo Integral - CETI Marcos Parente. Nesta pesquisa buscou-se avaliar a acessibilidade dos alunos ao uso de Ambientes Virtuais de Aprendizagem e aos Simuladores, bem como, verificar suas percepções com relação ao tema desse estudo.

Para conhecer o público estudado com relação aos conceitos sobre os AVAs e simuladores, foi aplicado um questionário contendo dez (10) questões objetivas, dividido em três vertentes sendo a primeira para analisar o conhecimento dos alunos sobre os AVAs, a segunda para identificar a ferramenta de pesquisa que o público utiliza para estudar e a terceira vertente saber se o professor da disciplina de Física utiliza algum tipo de tecnologia na sala ao trabalhar os conteúdos. Em seguida foram executadas aulas com uso de simuladores como proposta didática para o ensino de física em sala de aula.

\section{RESULTADOS E DISCUSSÃO}

Os estudantes ao serem indagados se eles possuem algum conhecimento sobre 0 que são AVAs e se já fizeram ou fazem o uso dessas ferramentas, bem como sua contribuição verificou-se que a grande maioria não conhece esses ambientes/ferramentas, conforme pode ser verificado na figura 1. 
Figura 1 - Nível de conhecimento sobre os AVAs (a) Você tem algum conhecimento sobre AVAs? (b) Você fez/faz o uso dos AVAs para aprendizagem de Física?

(a)

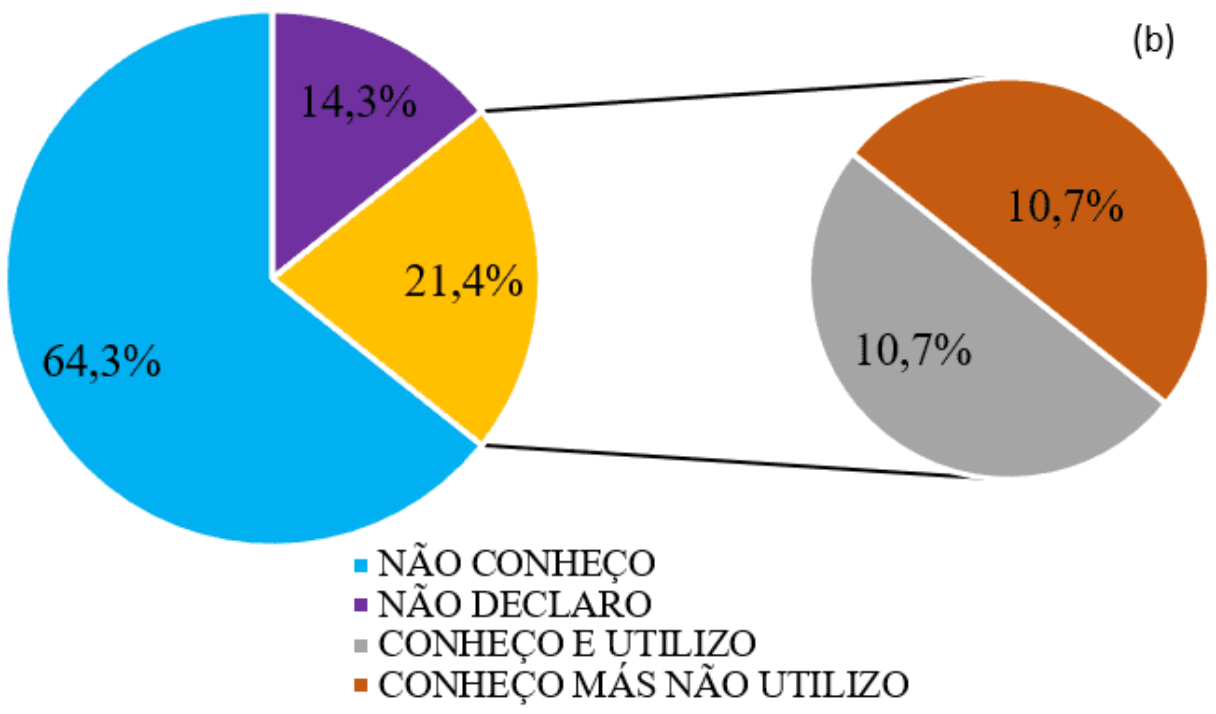

Fonte: Dados da pesquisa.

Apesar do número de alunos que conhecem os AVAs ser muito menor comparado aos que não conhecem, percebe-se que esse público nem sempre busca fazer a utilização do ambiente virtual (figura 1b). Isso pode estar associado a inúmeros fatores e uma das possibilidades pode ser a falta de familiaridade com essas ferramentas (sabem que existe, mas não sabem utilizar). Enquanto aos que utilizam mostraram-se satisfeitos, cerca de $7,1 \%$ dizem que os AVAs contribuem para a aprendizagem no Ensino de Física.

Quando se remete aos Ambientes Virtuais de Aprendizagem logo associa-se a diversos conceitos relacionados sobre o assunto, uma interpretação lógica seria assemelhar os AVAs como sendo um espaço virtual em uma rede que fornece todo material de aprendizagem. Para Salvador et al (2017), AVA é um ambiente que integra funcionalidades e ferramentas para o ensino/aprendizagem.

A utilização da internet se tornou tão indispensável e presente na vida das pessoas de tal forma que elas nem param para pensar se estão fazendo o uso de maneira correta, se as ferramentas utilizadas são realmente necessárias e os conteúdos 
disponibilizados são verdadeiros, uma vez que independente da natureza da pesquisa é preciso buscar sempre veracidade nas informações. O autor Moraes (2014) relata que a internet proporcionou pontos positivos e negativos, e os fatores positivos são quando a tecnologia é bem aplicada ajudando no processo de evolução social.

Com isso surge a questão da aprendizagem, os desafios encontrados pelo professor em sala de aula para atender as demandas na era tecnológica, o ensino presencial enfrenta o desafio de associar-se a esse contexto. Pensando em adaptar e deixar a sala de aula mais atrativa para os alunos de acordo com seu contexto histórico, surge como uma proposta pedagógica para o ensino, em especial o ensino de física, utilizar tecnologias em sala para abordagem de conteúdo.

No entanto, é preciso conhecer realmente o público, por isso a segunda vertente buscou analisar os estudantes em relação ao uso da internet como ferramenta de estudo. A primeira pergunta dessa vertente consistia em saber se eles usavam a internet para estudar. Neste quesito ouve unanimidade onde 100\% dos alunos responderam que sim. Na figura 2 é apresentado as principais ferramentas de estudo usadas pelos alunos.

Figura 2 - Tipo de ferramenta utilizada para estudo

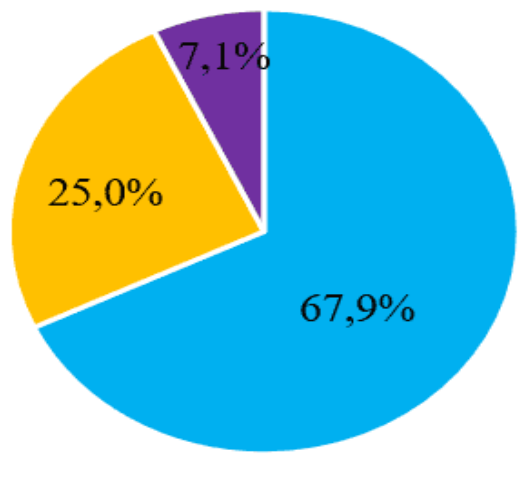

- USO GOOGLE E YOUTUBE

SOMENTE

GOOGLE

- SOMENTE YOU

TUBE

Fonte: Dados da pesquisa 
Dessa forma fica claro que apesar de inúmeras ferramentas já disponíveis na internet, boa parte dos estudantes acessam o navegador simplesmente para procurar a informação que desejam. O YouTube também é uma boa opção, pela vasta disponibilidade de vídeos sobre diversos assuntos, porém todos os conteúdos acessados precisam ser verificados quanto ao tipo de informações contidas.

Na figura 3 é mostrado a frequência da utilização das ferramentas citadas acima pelos alunos. Embora os estudantes sejam de uma escola de tempo integral, ainda assim mostra que esses estão à procura de meios para complementação da sua aprendizagem.

Figura 3- Frequência do uso da internet como ferramenta de estudo

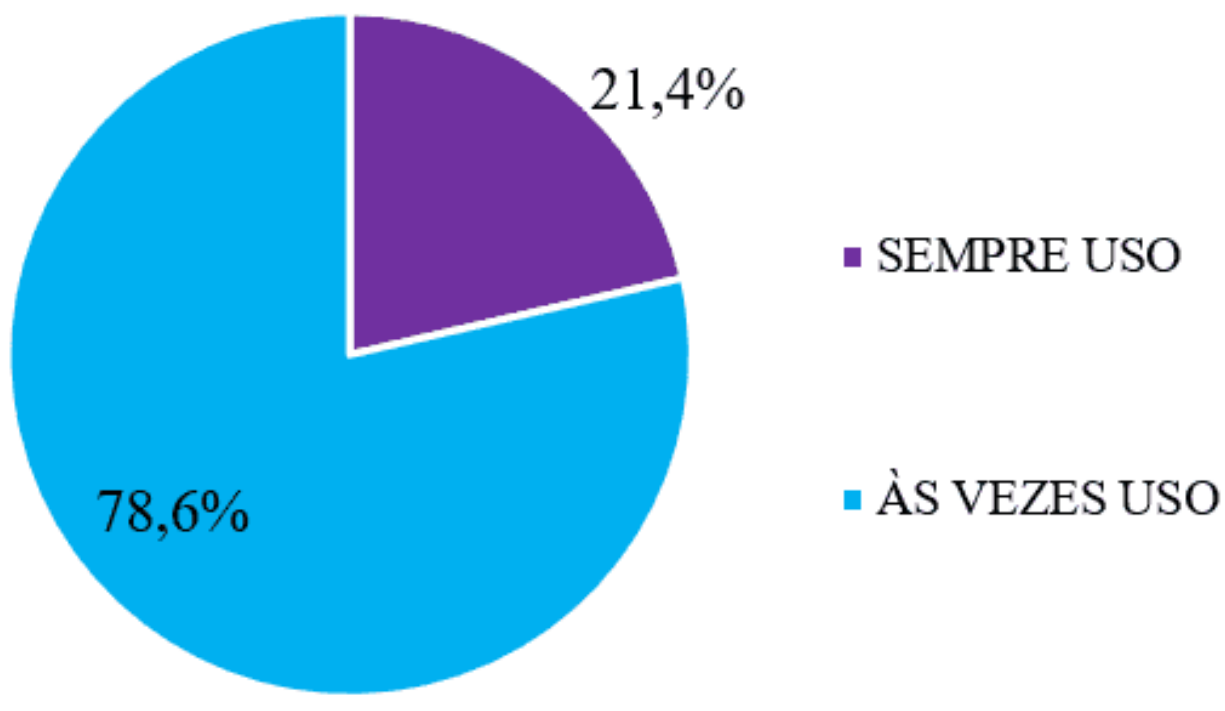

Fonte: Dados da pesquisa

Segundo os alunos, os professores não utilizam muito a tecnologia ao ministrarem as aulas. Apenas $28,6 \%$ afirmou que sim e a essa porcentagem atribui-se o entendimento do que é tecnologia (computador e projetor que as vezes o professor usa). Embora 10,7\% apontam que o professor já ministrou o conteúdo utilizando simulador, ainda 
assim resta uma dúvida sobre a percepção dos mesmos com relação ao estudo da pesquisa, esses resultados estão contidos na figura 4 pois a pesquisa foi realizada em uma única turma.

Figura 4- Uso de tecnologia em sala pelo professor de física.

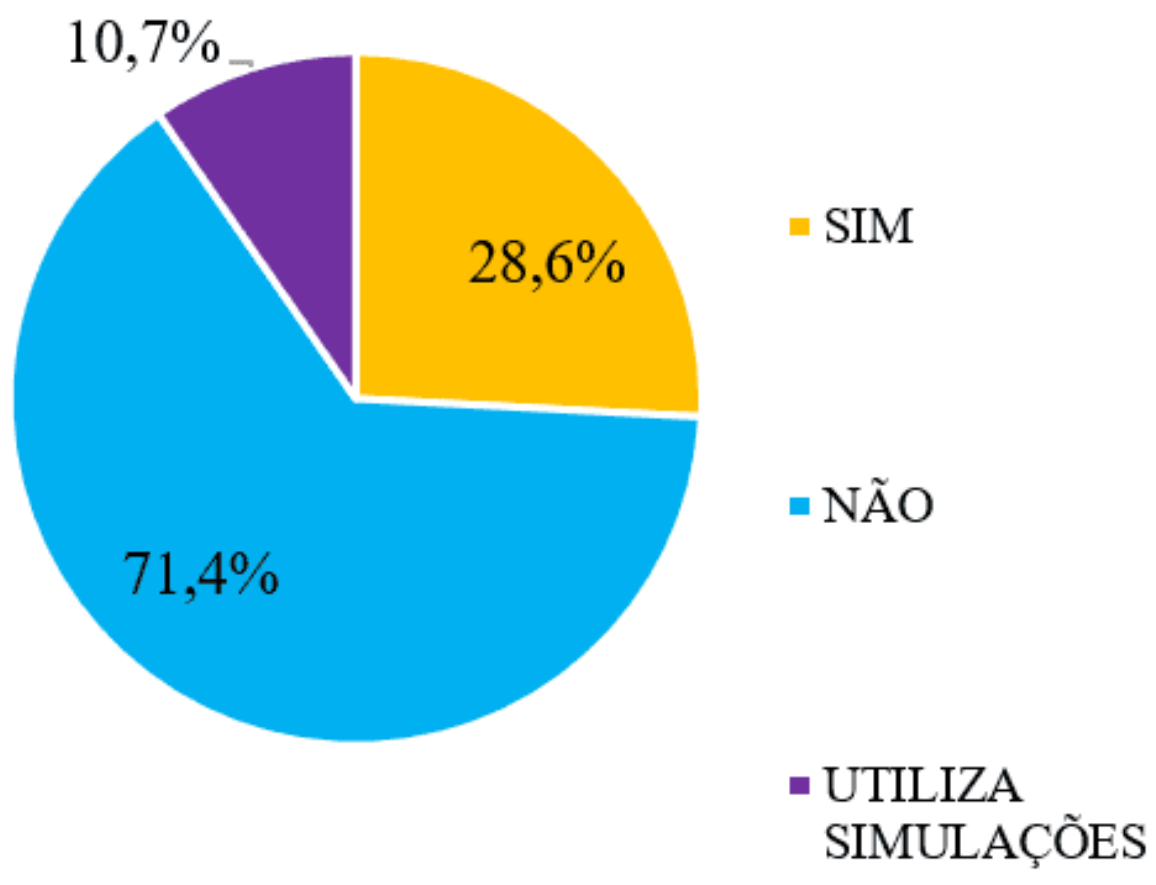

Fonte: Dados da pesquisa

Após os resultados obtidos com a aplicação do questionário, foi ministrado aulas para os alunos alvos da pesquisa. De início foi definido os conceitos sobre os Ambientes Virtuais de Aprendizagem (AVAs) e Ambientes Informatizado de Aprendizagem (AIA), bem como a importância, exemplos e aplicações desses ambientes na educação. A aula proposta permitiu tirar dúvidas e discussões relacionadas aos temas.

Além disso, foi apresentado a utilização dos simuladores. Como exemplo, foi utilizado o simulador phet, esse permite fazer simulações offline, utilizando apenas o computador e projetor. As simulações apresentadas aos alunos foram relacionadas ao movimento oblíquo de projeteis, ângulos, aceleração, velocidade, força e atrito, conteúdos já ministrados pelo professor titular da turma. 
Durante a aula, os alunos demonstraram interesse pela simulação e colocaram os seus conhecimentos em "prática", porém, foi verificado um ponto negativo durante as simulações, pois como era apenas um computador e projetor, não atendeu todos os alunos de forma ampla, com isso, houve dificuldade de organizar a turma para que todos tivessem oportunidade de manusear o programa. Apesar disso, os alunos mostraram satisfação e entusiasmo durante a aula.

\section{CONSIDERAÇÕES FINAIS}

De forma geral, a pesquisa realizada mostrou que apesar do contato direto com os meios tecnológicos, ainda é preciso direcionar os discentes a buscarem conceituação do que estão utilizando, além de fazê-los desenvolver um pensamento crítico e procurar se beneficiar do uso das redes sem haver prejudicados.

Os resultados obtidos na pesquisa consolidaram ainda mais a necessidade de solucionar a problemática atual. Para isso, deve levar essa proposta pedagógica para o âmbito educacional, favorecendo o ensino e a aprendizagem dos alunos para que esses tenham maior rendimento.

Por fim, pode se constatar que antes da aplicação de metodologias em sala de aula, deve-se conhecer o perfil da turma, o ambiente escolar e trabalhar com conceituação do tema estudado. Apesar da influência da tecnologia atualmente em nossas vidas, ainda há barreiras a ser superadas na educação.

\section{REFERÊNCIAS}

BENELI, L. de Melo. Didática da educação a distância: características e concepções de ensino. Revista de educação, v. 15, n. 19, p. 27 - 35, 2014.

CONCHETI, A. Fernanda. A pluralidade da relação entre a física e a matemática em um curso inicial de licenciatura em Física. 2015. 128 f. Dissertação (Ensino de Ciências) - Universidade de São Paulo, São Paulo, 2015. 
FERNANDES, Emerson Ferreira. As dificuldades de compreender Física dos alunos do ensino médio das escolas públicas de IGUATU - CE. Monografia (Licenciatura em Física) - Universidade Estadual do Ceará - UECE, Iguatu- CE, 2016.

LEÃO, Marcelo Franco et al. O uso de um ambiente virtual de aprendizagem como ferramenta de apoio ao ensino presencial. Abakós Instituto de Ciências Exatas e Informática, nov. 2013. Disponível em: file:///C:/Users/Raila\%20Leal/Downloads/583124008-1-PB.pdf. Acessado em: jan. 2019.

MARTINS, F. C. G.; et al. A pedagogia do oprimido e a práxis pedagógicas libertadora de Paulo Freire. Trabalho apresentado na XXII semana de Educação da Universidade Estadual do Ceará, [S. I], 2015.

MARTINS, D. de Oliveira; TIZIOTTO, S. A.; CAZARINI, E. W. Ambientes Virtuais de Aprendizagem (AVAs) como ferramentas de apoio em Ambientes Complexos de Aprendizagem (ACAs). Associação Brasileira de Educação a Distância. v. 15, n. 8, p. $114 \quad-\quad 130,2016 . \quad$ Disponível em: http://seer.abed.net.br/edicoes/2016/08_Ambientes_virtuais_aprendizagem.pdf. Acessado em: 24 jul. 2019.

MORAES, D. C. A internet como ferramenta tecnológica e as consequências de seu uso: aspectos positivos e negativos. Revista Cientifica Semana Acadêmica, v. 01, n. 55, p. 01- 17, 2014.

NETO, J. A. Sá de Pinho; VITAL, M. J. da Cruz. A inclusão digital nos telecentros de informação e educação do município de João Pessoa. Trabalho apresentado no XI Encontro Nacional de Pesquisa em Ciência da Informação Inovação e inclusão social: questões contemporâneas da informação, Rio de Janeiro, 2010. Disponível em: http://enancib.ibict.br/index.php/enancib/xienancib/paper/viewFile/3497/2622. Acessado em: 25 jul. 2019.

OLIVEIRA, Luciene de. Interação Professor- Aluno: elemento chave do processo de ensino - aprendizagem. 2010. 16 f. Artigo (Licenciatura em Letras)- Universidade Estadual do Paraíba, Guarabira - PB, 2010. 
PEREIRA, D. M.; et al. Tecnologia Interativa: simuladores e jogos educativos aplicados à motivação da educação infantil. Revista iTEC, v. 1, n. 1, p. 28 -31, 2010.

RIBEIRO, E. N.; MENDONÇA, G. A. de A.; MENDONÇA, A. F. de. A importância dos ambientes virtuais de aprendizagem na busca de novos domínios da EAD. Relatório de pesquisa, [S. I], 2007.

RIBEIRO, Maurílio Rizza. Análise das dificuldades relacionadas ao ensino de física no nível médio. 2005. 47 f. Monografia (Licenciatura em Física) - Universidade de Uberlândia, Uberlândia - MG, 2005. Disponível em: http://www.infis.ufu.br/infis_sys/pdf/MAURILIO\%20RIZZA\%20RIBEIRO.pdf. Acessado em 23 jul. 2019.

SALVADOR, P. T. C. de Oliveira.; et al. Objeto e ambiente virtual de aprendizagem: análise de conceito. Revista Brasileira de Enfermagem- REBEn, p. 599 - 606, 2017.

SANTOS, C. Ramos dos. Ambiente informatizado como meio para desenvolver a autonomia nos alunos. 2010. 43 f. Monografia (Licenciatura em Pedagogia) Universidade Federal do rio Grande do Sul, Alvorada, 2010.

SILVA, F. Figueiredo. Os desafios da educação na era digital. Pós-Graduação (Gestão e Tecnologia da Informação) - Instituto de Educação Tecnológica, [S. I], 2015.

SOUSA, L. M. Análise da eficácia do uso de simuladores computacionais no ensino de óptica. 2011. 33 f. Monografia (Licenciatura em Física) - Universidade Federal de Uberlândia, Uberlândia, 2011.

SCHUHMACHER, V. R. N.; Alves FILHO, J. P.; SCHUHMACHER, E. As barreiras da prática docente no uso das tecnologias de Informação e Comunicação. Ciênc. Educ., Bauru, v. 23, n. 3, p. 563-576, 2017.

ZAMPIER, Lucinéia. Simulador educacional como ferramentas de apoio em aulas de Ciências. Campina do Simão, 2016. Disponível em: 
http://www.diaadiaeducacao.pr.gov.br/portals/cadernospde/pdebusca/producoes_pd e/2016/2016_pdp_cien_unicentro_lucineiazampier.pdf . Acessado em: 26 jul. 2019.

Enviado: Julho, 2020.

Aprovado: Agosto, 2020. 